\title{
APLICAÇÃO DE MÉTODOS DE ANÁLISE FÍSICO-QUÍMICA PARA AVALIAÇÃO DE CAFÉS DESCAFEINADOS COMERCIALIZADOS EM FEIRA DE SANTANA
}

\author{
Larissa Silva Seixas ${ }^{1}$ e Luiz Severo da Silva Junior ${ }^{2}$ \\ 1. Bolsista PROBIC/UEFS, Graduanda em Engenharia de Alimentos, Universidade Estadual de Feira de Santana, e-mail: \\ larissa.sseixas@hotmail.com \\ 2. Orientador, Departamento de Tecnologia, Universidade Estadual de Feira de Santana, e-mail: severo@uefs.br
}

PALAVRAS-CHAVE: Café descafeinado; análise físico-química; validação.

\section{INTRODUÇÃO}

O café é uma das bebidas mais consumidas no mundo, além de ser um alimento muito estudado, devido às controvérsias geradas por seus malefícios ou benefícios. A cafeína é um alcaloide, pertencente ao grupo das xantinas, alguns estudos comprovam que "uma concentração elevada de cafeína pode afetar os rins, fígado e sistema nervoso" de acordo com Saldana et al. (1997). Segundo Silvarolla (2004), o café descafeinado corresponde a $10 \%$ do consumo mundial de café, justificando a importância de analisar técnicas de descafeinação e os teores de cafeína encontrados nesse café pós-torrefação. A validação de métodos analíticos é muito importante quando o assunto é análise físico-química, pois verifica se a análise realizada é adequada ao seu objetivo (Brito et al., 2003).

\section{MATERIAL E MÉTODOS OU METODOLOGIA}

As amostras de café descafeinados (três marcas comerciais) foram adquiridas em supermercados da cidade Feira de Santana - Bahia e analisadas no Laboratório de Análise Físico-Química de Alimentos, localizado no Laboratório de Tecnologia II (Labotec II), na Universidade Estadual de Feira de Santana (UEFS). Foram realizadas análises de pH, resíduo seco, umidade, cinzas e cafeína de acordo com os métodos descritos pelo Instituto Adolfo Lutz (IAL). Determinou-se a acidez por potenciometria segundo a faixa de viragem estabelecida por Texeira et al. (2016).

\section{RESULTADOS E DISCUSSÃO DOS RESULTADOS}

1. Aplicação dos parâmetros de validação

Após a calibração do pHmetro, avaliou-se o pH quanto a repetitividade, o mesmo procedimento foi realizado em outro equipamento a fim de verificar a robustez e a reprodutibilidade do método. Indiretamente pode-se averiguar a sensibilidade de equipamentos diferentes e seu comportamento diante da mesma amostra. Para a análise de acidez foram aplicados os parâmetros de repetitividade, robustez (usou-se diferentes molaridades de $\mathrm{NaOH}$ ) e sensibilidade, a qual foi avaliada a partir da mudança nos volumes da amostra analisada e como isso se traduzia na resposta do equipamento.

Avaliou-se a sensibilidade do Aqualab ao medir a atividade de água (aw) existente no café torrado e moído, a partir do parâmetro de robustez, no qual foram feitas pequenas e deliberadas alterações na massa. Para análise de resíduo seco, as amostras de infusão foram colocadas na estufa Nova Técnica a $105^{\circ} \mathrm{C}$. A robustez foi avaliada a partir de mudanças no volume da infusão. O mesmo procedimento foi feito na estufa Quimis, aplicando a reprodutibilidade e a robustez em relação à temperatura. As amostras de cinzas foram colocadas inicialmente no equipamento de referência, com a temperatura de $550{ }^{\circ} \mathrm{C}$ e a massa de café por cadinho foi variada. Para robustez, foi usada a temperatura de $560^{\circ} \mathrm{C}$ e massa de 
café fixa. Na segunda mufla foi usada temperatura de $550{ }^{\circ} \mathrm{C}$ e massa fixa de café. Na tabela 1, podemos ver os resultados das análises com os parâmetros de validação já aplicados.

Tabela 1. Métodos de validação aplicado às análises físico-químicas.

\begin{tabular}{ccc}
\hline Análise & Parâmetro de Validação & Resultado \\
\hline \multirow{2}{*}{$\mathbf{p H}$} & Repetitividade & $5,22 \pm 0,006$ \\
& Reprodutibilidade & $5,20 \pm 0,006$ \\
pH (i) & Robustez & $5,21 \pm 0,01$ \\
& Repetitividade & $5,33 \pm 0,02$ \\
& Reprodutibilidade & $5,24 \pm 0,01$ \\
Acidez & Robustez & $5,36 \pm 0,02$ \\
& Repetitividade & $2,56 \%(\mathrm{v} / \mathrm{v})$ \\
\multirow{2}{*}{ Acidez (i) } & Reprodutibilidade & $2,56 \%(\mathrm{v} / \mathrm{v})$ \\
& Robustez & $0,40 \%(\mathrm{v} / \mathrm{v})$ \\
& Repetitividade & $1,11 \%(\mathrm{v} / \mathrm{v})$ \\
\multirow{2}{*}{ aW } & Reprodutibilidade & $1,11 \%(\mathrm{v} / \mathrm{v})$ \\
& Robustez & $4,2 \%(\mathrm{v} / \mathrm{v})$ \\
& Repetitividade & $0,355 \pm 0,006$ \\
& Robustez & $0,350 \pm 0,008$ \\
Resíduo seco & Sensibilidade & $0,353 \pm 0,009$ \\
& Repetitividade & $2,76 \%(\mathrm{~m} / \mathrm{v})$ \\
& Reprodutibilidade & $2,76 \%(\mathrm{~m} / \mathrm{v})$ \\
Cinzas & Robustez & $2,71 \%(\mathrm{~m} / \mathrm{v})$ \\
& Robustez & $3,8 \%(\mathrm{~m} / \mathrm{m})$ \\
Cafeína & Reprodutibilidade & $4,39 \%(\mathrm{~m} / \mathrm{m})$ \\
& Sensibilidade & 0,250 \\
& (absorbância) & 0,251 \\
& & 0,252 \\
\hline
\end{tabular}

Legenda: (i) infusão.

2. Análises físico-químicas em cafés descafeinados comercializados em Feira de Santana

Dentre as marcas de cafés descafeinados comercializadas em Feira de Santana, foram escolhidas três marcas comerciais, com base na preferência do consumidor. Por questões de sigilo, as marcas serão chamadas de amostras A, B e C. As análises realizadas são as mesmas listadas na tabela 1 .

Tabela 2. Marcas adquiridas para análise.

\begin{tabular}{cccc}
\hline Marca & Validade & Lote & Local da Compra \\
\hline A & $02 / 12 / 2018$ & 18L27 RN 03 07:40 & Feira de Santana \\
B & $08 / 01 / 2019$ & L03:01 2J & Feira de Santana \\
C & $13 / 01 / 2019$ & PKD 193M 02:13 & Feira de Santana \\
\hline
\end{tabular}

Com o objetivo de reproduzir as condições reais nas quais o café é feito nas residências, esse estudo analisou a infusão do café, para verificar as características das bebidas prontas nas quais são consumidas. Outras análises foram feitas com o café moído torrado, a fim de avaliar se a marca está adequada aos padrões estabelecidos pela legislação. Na tabela 3 seguem os resultados obtidos com as análises.

Tabela 3. Análises físico-químicas nos cafés descafeinados selecionados. 


\begin{tabular}{cccc}
\hline Análise & Amostra A & Amostra B & Amostra C \\
\hline pH & $5,22 \pm 0,006$ & $5,16 \pm 0,006$ & $5,29 \pm 0,006$ \\
pH (i) & $5,33 \pm 0,01$ & $5,19 \pm 0,03$ & $5,34 \pm 0,03$ \\
Acidez & $2,56 \%(\mathrm{v} / \mathrm{v})$ & $2,42 \%(\mathrm{v} / \mathrm{v})$ & $2,42 \%(\mathrm{v} / \mathrm{v})$ \\
Acidez (i) & $1,11 \%(\mathrm{v} / \mathrm{v})$ & $1,11 \%(\mathrm{v} / \mathrm{v})$ & $1,51 \%(\mathrm{v} / \mathrm{v})$ \\
aW & $0,355 \pm 0,01$ & $0,361 \pm 0,01$ & $0,277 \pm 0,03$ \\
Resíduo seco & $2,76 \%(\mathrm{~m} / \mathrm{v})$ & $1,36 \%(\mathrm{~m} / \mathrm{v})$ & $1,38 \%(\mathrm{~m} / \mathrm{v})$ \\
Umidade & $3,9 \%(\mathrm{~m} / \mathrm{m})$ & $4,60 \%(\mathrm{~m} / \mathrm{m})$ & $3,07 \%(\mathrm{~m} / \mathrm{m})$ \\
Cinzas & $4,39 \%(\mathrm{~m} / \mathrm{m})$ & $3,72 \%(\mathrm{~m} / \mathrm{m})$ & $4,12 \%(\mathrm{~m} / \mathrm{m})$ \\
\hline
\end{tabular}

Legenda: (i) infusão.

$\mathrm{O}$ pH é um importante indicador da qualidade dos alimentos, para o café não seria diferente. $\mathrm{O}$ café moído apresentou $\mathrm{pH}$ menor do que a amostra da infusão, o que pode ter relação com a presença de resíduos ou traços de cafeína, que é extraída com a água quente durante o seu preparo. No caso da infusão, foram encontrados valores de $\mathrm{pH}$ similares entre as amostras analisadas, os quais estão num intervalo que conferem a infusão sabor agradável (Fernandes et al., 2003).

$\mathrm{Na}$ titulação da acidez da amostra enquanto pó foi possível verificar uma acidez considerável, visto que as partículas que ficam em suspensão tornam o procedimento mais laborioso, fazendo com que se gaste maior quantidade de titulante do que na análise da infusão. Alimentos que com baixa atividade de água (menor ou igual a 0,3), como os cafés estudados nesse trabalho, tem sua água livre na monocamada, significando que a mesma não está disponível para participar de reações químicas e enzimáticas, logo não contribui para o crescimento de microrganismos (Ribeiro \& Seravalli, 2007). O resíduo seco obtidos para as amostras B e C apresenta similaridade entre si e diferem da A, podendo ter alguma relação com as variáveis que envolvem a execução da análise, como o analista, os equipamentos de medição (balança, vidrarias e estufa), bem como a matéria-prima.

Os teores de umidade e de cinzas são análises de suma importância para a caracterização de cafés, visto que ambas dizem respeito às práticas da indústria processadora de café, pois a umidade está relacionada com procedimentos de armazenamento correto dos grãos e a segunda está sujeita a assumir valores superiores ao indicado pela RDC n ${ }^{\circ}$ 277/2005 (BRASIL, 2005) caso materiais inadequados sejam adicionados durante o processo de torra e moagem, configurando um adulterante no café. A Legislação estabelece que a umidade seja de no máximo $5,0 \%(\mathrm{~g} / 100 \mathrm{~g})$, em todas as marcas avaliadas o valor encontrado estava abaixo desse limite; o mesmo percentual limítrofe se aplica para o teor de cinzas, de acordo com Brasil (2010). Todas as amostras, assim como na análise de umidade, encontraram-se abaixo da quantidade estipulada.

Para o preparo das amostras da análise de cafeína, foi realizada uma extração líquidolíquido a quente com água, o clorofórmio foi usado como solvente. Na figura 1 e na tabela 4 podem ser vistos, respectivamente, a curva de calibração obtida e os resultados da análise de cafeína nos cafés descafeinados.

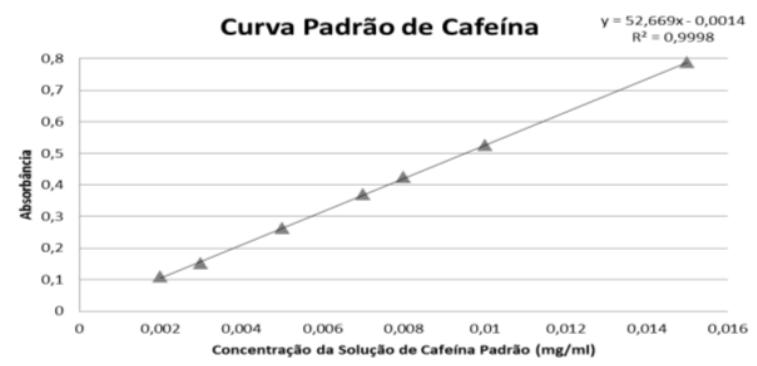

Figura 1. Curva padrão de cafeína. 
Tabela 4. Resultados da análise de cafeína para as marcas estudadas.

\begin{tabular}{cccc} 
& Amostra A & Amostra B & Amostra C \\
\hline Absorbância & $0,251 \pm 0,001$ & $0,319 \pm 0,001$ & $0,282 \pm 0,002$ \\
Cafeína \% (g/100g) & 0,047 & 0,060 & 0,053 \\
\hline
\end{tabular}

Os métodos de descafeinação não alcançam $100 \%$ de eficiência, por isso observa-se que mesmo após passar pelo procedimento, resta uma fração desse componente no café descafeinado. Os resultados da análise espectrofotométrica revelam as marcas selcionadas encontram-se dentro do padrão estabelecido pela $\mathrm{RDC} \mathrm{n}^{\circ} 277 / 2005$, fator positivo frente ao consumidor, uma vez que a grande maioria destes adquire este tipo de café devido a recomendações médicas.

\section{CONSIDERAÇÕES FINAIS}

Foi possível aplicar parâmetros de validação nas análises físico-químicas, bem como caracterizar os cafés descafeinados disponíveis no mercado consumidor de Feira de Santana Bahia. Além disso, determinou-se o teor de cafeína e compará-lo com a legislação vigente, estando todos dentro dos limites máximos especificados.

\section{REFERÊNCIAS}

ABRAHÃO, S. A.; PEREIRA, R. G. F. A.; LIMA, A. R.; FERREIRA, E. B.; MALTA, M. R. Compostos bioativos em café integral e descafeinados e qualidade sensorial da bebida. Pesq. agropec. bras., v. 43, n. 12, p.1799-1804, 2008.

BRASIL. Agência Nacional de Vigilância Sanitária. RDC no 277, de 22 de setembro de 2005. Aprova o "Regulamento técnico para café, cevada, chá, erva-mate e produtos solúveis".

Diário Oficial da União, Brasília, n. 184, 23 set. 2005.

BRASIL. Secretaria da Agricultura e Abastecimento do Estado de São Paulo. Resolução SAA no 19 , de 5 de abril de 2010. Norma de padrões mínimos de qualidade para café torrado em grão e torrado e moído - café tradicional. Diário Oficial do Estado de São Paulo, São Paulo, 04 abr. 2010.

BRITO, N. M. et al. Validação de métodos analíticos: estratégia e discussão. Pesticidas: R.

Ecotoxicol. e Meio Ambiente, v. 13, p. 129-146, 2003.

INSTITUTO ADOLFO LUTZ. Métodos físico-químicos para análise de alimentos / coordenadores Odair Zenebon, Neus Sadocco Pascuet, e Paulo Tiglea. São Paulo: Instituto Adolfo Lutz, 4 ed., 2008. 1020 p.

FERNANDES, S. M.; PEREIRA, R. G. F. A.; PINTO, N. A. V. D.; NERY, M. C.; PÁDUA, F. R. M. Constituintes químicos e teor de extrato aquoso de cafés arábica (Coffea arábica L.) e conilon (Coffea canephora Pierre) torrados. Ciência e Agrotecnologia, Lavras, v. 27, n. 5, p. 1076-1081, set./out. 2003.

RIBEIRO, E. P.; SERAVALLI, E. A. G. Química de Alimentos. $2^{\text {a }}$ Edição. São Paulo: Blucher, 2007.

SALDANA, Marleny D. A.; MAZZAFERA, Paulo; MOHAMED, Rahoma S.. EXTRAÇÃO DOS ALCALÓIDES: Cafeína e trigonelina dos grãos de café com c supercrítico. Ciênc.

Tecnol. Aliment., v. 17, n. 4, p. 371-376, 1997.

SILVAROLLA, M. B.; MAZZAFERA, P.; FAZUOLI, L. C.; Nature. 2004.

TEXEIRA, O. R.; PASSOS, F. R.; MENDES, F. Q. Qualidade Físico-Química e Microscópica de 14 Marcas Comerciais de Café Torrado e Moído. Coffee Science, v. 11, n. 3, p. 395-402, 2016. 